\title{
Long-term survival of patients with breast cancer: a study of the curability of the disease
}

\author{
ALLAN O LANGLANDS, STUART J POCOCK, GILLIAN R KERR, SHEILA M GORE
}

British Medical fournal, 1979, 2, 1247-1251

\section{Summary and conclusions}

A retrospective analysis was made of 3878 cases of breast carcinoma first seen in Edinburgh from 1954 to 1964. During this time there was a policy to treat breast cancer by simple mastectomy and x-ray therapy, and over $90 \%$ of cases classified as international stages I and II were so treated. The mortality in these women was compared with that in an equivalent normal population using Scottish national age-specific death rates. For every year of follow-up within 20 years of initial treatment there was an excess mortality from all causes. There was an overall excess mortality of $58 \%$ among patients with breast cancer 15-20 years after initial treatment, and 20 times more deaths occurred in this period from breast cancer than in a normal population. For patients diseasefree after 15 years there was still a $28 \%$ excess mortality from all causes.

Factors known to be of major prognostic significance for five-year survivorship had less influence than might have been expected when the ratio of observed to expected deaths was considered for longer periods of follow-up. The effect of clinical staging (I, II, or III), though initially marked, largely disappeared by the 10th year of followup, and after allowing for age there was no evidence

\footnotetext{
Department of Radiotherapy, Edinburgh Royal Infirmary and Western General Hospital, Edinburgh

ALLAN O LANGLANDS, BSC, FRCR, consultant radiologist (present address: Department of Radiotherapy, Westmead Centre, PO Box 264, Westmead, NSW 2145, Australia)

GILLIAN R KERR, BSC, MSC, lecturer in statistics

Department of Clinical Epidemiology and Social Medicine, Royal Free Hospital School of Medicine, London NW3 2PN

STUART J POCOCK, BA, PHD, senior lecturer in medical statistics

Department of Statistics, University of Aberdeen, Aberdeen SHEILA M GORE, MA, lecturer in statistics
}

beyond 10 years of an effect on survival of the original stage of the disease. Similarly, the effect of tumour size on survival disappeared after 10 years. Women who were premenopausal at presentation still had a significant excess of deaths in the fourth quinquennium of follow-up. In the menopausal and postmenopausal groups combined there was still a small non-significant excess of deaths from all causes after 15 years but this almost disappeared when patients who had already relapsed were excluded.

In terms of overall mortality only patients who have undergone the menopause before presentation and who are disease-free 15 years after primary treatment may prove to be cured by conventional techniques such as simple mastectomy and postoperative radiotherapy.

\section{Introduction}

Increasing awareness of the natural history of breast cancer has had two major effects on the presentation of survival data. Firstly, it has led to the recognition that conventional fixed-time survival at five or 10 years is not synonymous with cure ${ }^{1}$ and as a result there has been increasing use of life-table analysis. Secondly, the fact that relapse can occur many years after initial treatment makes it necessary not only to continue follow-up for 20 years or more but also to allow for the normal mortality experience in the general population. ${ }^{2}$

Several authors have analysed survival data taking these considerations into account and have attempted to assess the curability of breast cancer by investigating whether the observed overall mortality of a group of patients eventually approached the expected mortality in a normal population of the same age. ${ }^{3-6}$ Easson and Russell could not identify a cured proportion of patients by the 15 th year after initial treatment, though the observed mortality of their main study group of 1812 operable cases was only $1 \%$ per annum in excess of expected mortality during the 10-15-year period. Nevertheless, they emphasised the need for a follow-up longer than 15 years. Brinkley and Haybittle, in a 25-year study of 704 women, suggested that after 21 years observed and expected mortalities were the same and interpreted this to mean that $30 \%$ of women with stage I and II disease were cured. In contrast, Duncan and Kerr concluded that 
patients with tumours larger than $3 \mathrm{~cm}$ but with no evidence of spread beyond the breast had a normal life expectancy 12 years after treatment, but for patients with smaller tumours normal life expectancy might not be observed until after 20 years.

In spite of these estimates of curability, analysis of the deaths that occur more than 20 years after treatment have shown that breast cancer remains significantly more common as a cause of death than in the general population. Of all women who die after developing cancer of the breast, $80-85 \%$ do so from their disease. ${ }^{7} 8 \mathrm{~A}$ cured group, if it exists, may therefore be smaller than that suggested by Brinkley and Haybittle.

Little information exists on the effect that various prognostic factors might have on curability. Brinkley and Haybittle concluded that patients with stage I and II disease had a higher probability of cure, while Duncan and Kerr studied the effect of tumour size but only for cases with no evidence of spread beyond the breast. We know of no previous study relating the menstrual status of the patient at presentation to the curability of the disease in spite of its well-recognised significance in terms of fixed-time survival rates. ${ }^{9-11}$

We report here a study of survival in a series of 3878 patients in which we evaluated the influence of three prognostic variables - stage of the disease, tumour size, and menstrual status-on the curability of breast cancer.

\section{Patients and methods}

A computer-based data file was established by abstracting clinical information from the case records of all patients with breast cancer referred to the department of radiotherapy, Edinburgh, from 1 January 1954 to 31 March 1964. The patient's status was established each year on the anniversary of first treatment and cases were dismissed from follow-up at 20 years if there was no recurrent disease. Cases referred for the management of recurrent disease were excluded from this review as were cases treated elsewhere but referred for follow-up. Of the original 3924 cases seen in this period, 46 were excluded from this study: two were initially treated before 1954, four had bilateral disease, and 40 were aged over 85 years at presentation. This left 3878 cases for analysis.

Over the period of the review two different staging systems were used. All cases were therefore restaged by the international TNM system. ${ }^{12}{ }^{13}$ There was insufficient detail to permit staging by TNM criteria in 85 cases. Menstrual status at presentation was known for 3680 patients on the basis of the patient's statement as to whether menstrual bleeding was occurring or not, irrespective of its regularity. They were subdivided into three groups: 1064 who were premenopausal, 450 who were menopausal-that is, less than five years past the menopause-and 2166 who were postmenopausal-more than five years past the menopause.

During the period under review the treatment policy of the department of radiotherapy, Edinburgh, was for simple mastectomy of the breast to be followed by postoperative radiotherapy. ${ }^{14}$ Seventy-five percent of all patients in this series, and over $90 \%$ of those with stage I or II disease, were treated in this way. We did not restrict our analysis to those treated by simple mastectomy and $x$-ray therapy since we considered that more reliable data on overall survival and the effects of staging were obtained by including all patients.

In the survival analysis patients were removed from further follow-up on reaching their 85th birthday. This was done, firstly, because national age-specific death rates are not accurately known for people aged 85 years or more and, secondly, because this prevented the analysis being affected by undue concentration on elderly deaths. Life-table analyses were based on six-monthly intervals during the first four years of follow-up (when mortality was at its highest) and yearly intervals thereafter. The main results concentrate on deaths from all causes. Allowance is made for the expected mortality from causes other than breast cancer by reference to the age-specific death rates in the Scottish national population. The resultant ratio of observed to expected deaths for various periods of follow-up forms the basis of statistical comparison. ${ }^{15}$ This ratio and the excess death rate have been used in preference to age-corrected life tables since the former give a more direct interpretation of mortality within any specific interval of follow-up-for example, 15-20 years.

Although each death was classified as due to either breast cancer or other causes on the basis of available knowledge including the review of hospital records and death certificates, we acknowledge that this information is not sufficiently reliable or objective ${ }^{2}$ and hence is included only as secondary evidence.

\section{Results and comment}

\section{OVERALL SURVIVAL EXPERIENCE}

Figure 1 shows the life table survival curve for all 3878 patients. Median survival was 4.6 years, with an estimated $31 \%$ surviving 10 years and $18 \%$ surviving 20 years. The international stage of the disease had a pronounced effect on survival: the median survival times were 9.7 years, 6.6 years, 2.9 years, and 0.7 years for stages I-IV respectively. The influence of different staging criteria on the presentation of survival data in this series has been dealt with in detail elsewhere. ${ }^{13}$

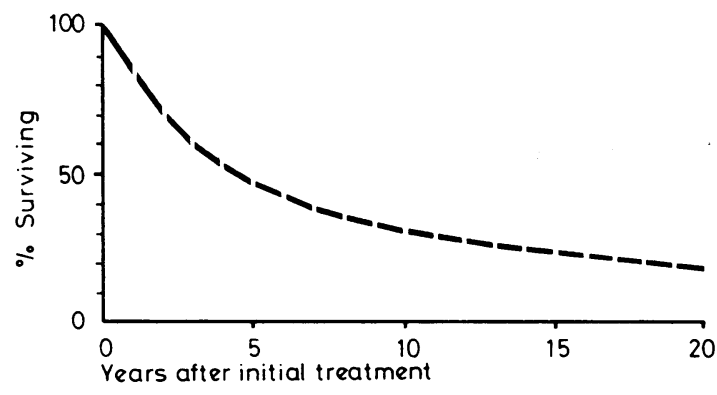

FIG 1-Life table percentage survival for all 3878 patients.

\section{SURVIVAL YEAR BY YEAR}

Survival was also analysed by considering the percentage dying of those alive at the start of each year of follow-up, firstly for all 3878 patients. A peak mortality of $16.3 \%$ in the first year fell continuously to a constant average mortality of $4.8 \%$ over the 16 th to 20 th years of follow-up. A different pattern emerged when this analysis was carried out according to the stage of the disease (fig 2).

Stage $I$-Mortality was low initially $(4.5 \%)$ in the first year of follow-up, rising to a peak of $9.4 \%$ in the 4 th year, after which the curve for stage I disease declined to an average of $4.4 \%$ over the 17 th to 20 th years.

Stage $I I$ - The mortality in the 1 st year was also low $(5.3 \%)$. Over the next four years it reached a maximum of $11 \%$ to $12 \%$. It then

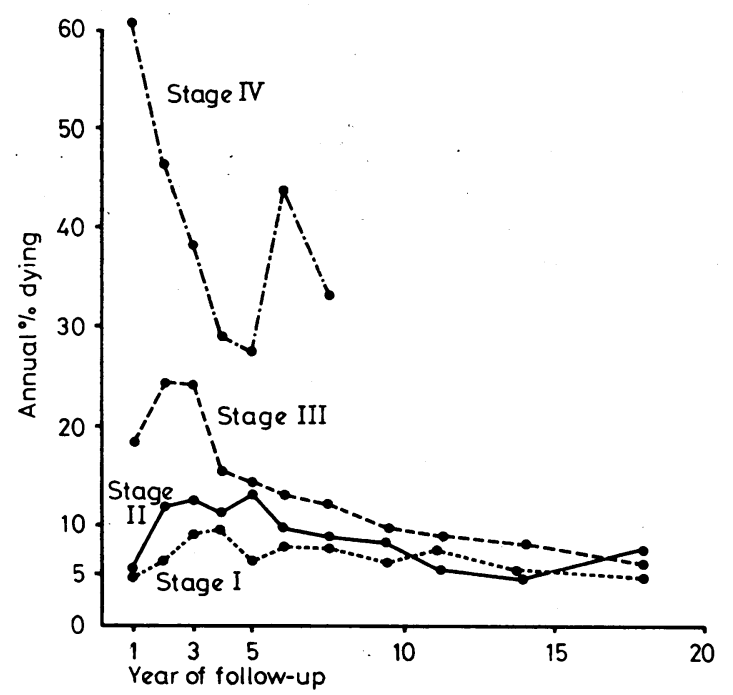

FIG 2-Mortality year by year according to international stage of disease. To prevent curves becoming too erratic due to small numbers of deaths in individual years, two-year averages are given beyond 7 years and four-year averages beyond 13 years. 
declined until, beyond 10 years, there was no clear distinction between the annual death rates for stages I and II. This means that for patients with stage I or II disease who survived 10 years the prognosis thereafter was the same.

Stage III-Annual mortality increased from $18 \%$ in the first year to over $23 \%$ during the second and third years of follow-up. Thereafter the annual mortality rate declined rapidly until it was below $10 \%$ after nine years. Beyond 15 years stage III patients assumed the same mortality experience (about $5 \%$ ) as those with stage I or II disease.

Stage IV-Sixty percent of patients died in the first year. Even for those still alive three years after presentation the average mortality remained greater than $30 \%$ a year. The curve was discontinued beyond eight years since there were only eight stage IV patients still alive.

Fig 3 shows the annual percentage of patients dying according to their menstrual state (excluding stage IV). In the first three years menopausal patients had the highest mortality but after five years

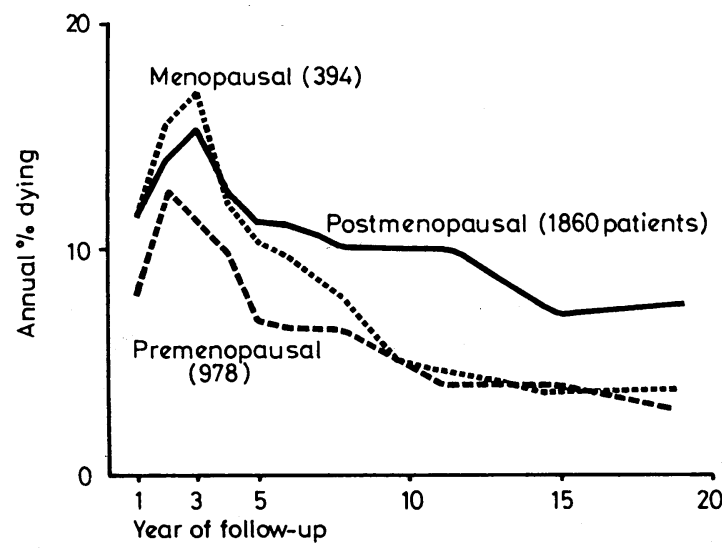

FIG 3-Mortality year by year according to menstrual status at presentation. To prevent curves becoming too erratic due to small numbers of deaths in individual years, two-year averages are given beyond 7 years and four-year averages beyond 13 years.

postmenopausal patients had the worst overall prognosis. This latter effect was due to the greater mortality to be expected in such an older group from causes other than breast cancer. After nine years the prognosis of menopausal patients was as good as that of premenopausal patients, even though the latter tended to be younger.

\section{COMPARISON WITH EXPECTED MORTALITY}

One possible definition of cure in a diseased group is that after a certain period of follow-up the group assumes the mortality pattern of a standard population with the same age distribution. We therefore compared the survival of our breast cancer patients with Scottish national mortality data to determine whether cure could be declared within 20 years of initial treatment.

Figure 4 shows the ratio of observed to expected deaths for the series as a whole. The ratio fell from 8.3 in the first year to 2.6 in the 10 th year of follow-up. Thereafter, because of the smaller numbers left, the ratio varied from year to year but remained greater than one throughout. More reliable information was obtained when we used periods of follow-up longer than one year, as in table I. There was a large excess mortality among the patients up to 15 years after initial treatment. From 15 to 20 years there was still a $58 \%$ excess mortality, which was very highly significant $(\mathbf{P}<0.001)$, and the $95 \%$ confidence limits indicated that the real excess for all breast cancer patients at this stage was somewhere between $25 \%$ and $98 \%$. Even after 17 years' follow-up there was still some evidence of excess mortality $(P<0.05)$, though the numbers thereafter were too small for definite conclusions.

Thus it seems unlikely that patients in this series as a whole could be considered cured after 17 years' follow-up, but more need to be followed up to 20 years before deciding for certain. Although 141 patients were still alive on the 20th anniversary of first treatment, a further 625 patients are still alive but have been followed up for less than 20 years, and of these, 254 have been followed up for less than 15 years. For the purpose of statistical analysis an additional 116 patients

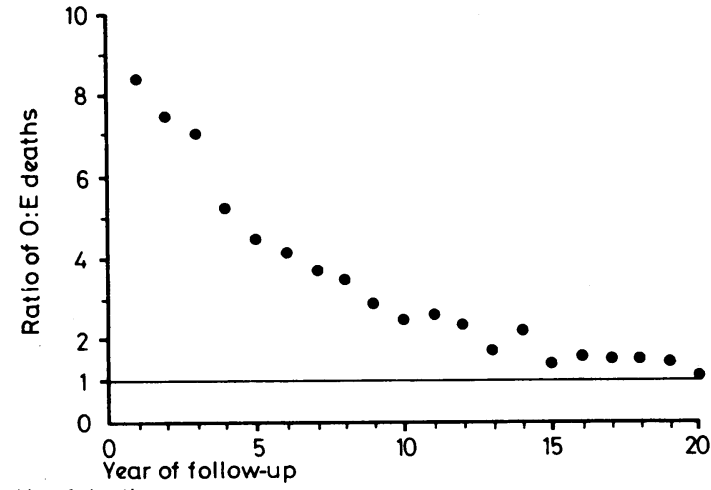

No of deaths:

Observed

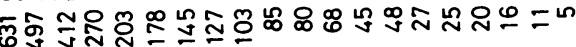

Expected

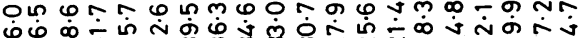

FIG 4-Ratio of observed to expected deaths for whole series by year of follow-up.

were removed from further follow-up once they reached their 85 th birthday.

An alternative method of expressing the excess mortality of breast cancer patients (the difference between observed and expected deaths) is in terms of the number of woman-years of follow-up-that is, as an excess death rate per year (see table I). Thus at 15-20 years the excess death rate was 18.8 per 1000 woman-years, or just under $2 \%$ a year.

TABLE I-Comparative mortality in 3878 cases of breast cancer

\begin{tabular}{|c|c|c|c|c|c|}
\hline Follow-up & $\begin{array}{c}\text { Observed } \\
\text { deaths }\end{array}$ & $\begin{array}{c}\text { Expected } \\
\text { deaths* }\end{array}$ & $\begin{array}{c}\text { Ratio } \\
\mathrm{O}: \mathrm{E}\end{array}$ & $\begin{array}{c}95 \% \\
\text { Confidence } \\
\text { limits for } \\
\text { ratio }\end{array}$ & $\begin{array}{c}\text { Excess } \\
\text { death rate } \\
1000 \\
\text { woman- } \\
\text { years } \S\end{array}$ \\
\hline $\begin{array}{l}0-5 \text { years } \\
5-10 \text { years } \\
10-15 \text { years } \\
15-20 \text { years }\end{array}$ & $\begin{array}{r}2013 \\
638 \\
268 \\
77\end{array}$ & $\begin{array}{r}298 \cdot 5 \\
186.0 \\
123.9 \\
48.7\end{array}$ & $\begin{array}{l}6.74 \dagger \\
3.43 \dagger \\
2 \cdot 16 \dagger \\
1.58 \dagger\end{array}$ & $\begin{array}{l}6 \cdot 45-7 \cdot 05 \\
3 \cdot 17-3 \cdot 71 \\
1.91-2 \cdot 44 \\
1 \cdot 25-1.98\end{array}$ & $\begin{array}{r}130.8 \\
63.1 \\
33.4 \\
18.8\end{array}$ \\
\hline $17-20$ years & 32 & 21.8 & $1 \cdot 47 \ddagger$ & $1.00-2.07$ & $16 \cdot 0$ \\
\hline
\end{tabular}

*Based on Scottish age-specific death rates. $\nmid P<0.001, \ddagger P<0.05$ comparing observed *Based on Scottish age-specific death rates. $+\mathrm{P}<0.001,+\mathrm{P}<0.05$ comparing observed
ratio with 1 . \$Defined as (observed :expected deaths) $\times 1000 /$ woman-years at risk.

For all deaths in this study we assessed whether the underlying cause was breast cancer. Of the 77 deaths in the 15-20 year follow-up period, $32(42 \%)$ were attributed to breast cancer compared with an expected 1.6 deaths from breast cancer in a normal population of the same age. This twentyfold excess in deaths from breast cancer after 15 years is consistent with previous findings. ${ }^{34}$

It is worth considering whether the overall excess mortality at 15-20 years after initial treatment can be attributed to patients who had relapsed before 15 years and could therefore be expected to die anyway. Of the 500 patients alive 15 years after treatment, 70 already had local or distant recurrence of disease. When such patients were excluded there were 54 deaths beyond 15 years compared with $42 \cdot 2$ expected. This $28 \%$ excess of deaths was significant (one-tail test $\mathrm{P}<0.05$ ) but was considerably less than the $58 \%$ excess when the relapsed patients were included. Hence, for patients who were diseasefree at 15 years there is a somewhat more optionistic outlook. Even so 11 of the 54 deaths were attributed to breast cancer, which was still considerably more than expected.

Similarly, when patients with a disease-free interval of under 10 years were excluded, the excess of observed to expected deaths 10-15 years after initial treatment fell to $44 \%$ compared with the earlier figure of $116 \%$ when relapsed patients were included.

Effect of clinical staging-Table II shows the ratio of observed, to expected deaths according to the international stage of the disease. After 10 years' follow-up the ratios for stages I, II, and III were very similar. A goodness of fit test $\left(\chi^{2}=0.54 ; 2 \mathrm{DF}\right)$ showed no significant difference between these ratios, indicating that after 10 years there 
TABLE II-Mortality according to international stage of disease for whole series of 3878 women

\begin{tabular}{|c|c|c|c|c|}
\hline Follow-up & $\begin{array}{l}\text { International } \\
\text { stage }\end{array}$ & $\begin{array}{l}\text { Observed } \\
\text { deaths }\end{array}$ & $\begin{array}{c}\text { Expected } \\
\text { deaths }\end{array}$ & $\begin{array}{c}\text { Ratio O:E } \\
\text { deaths }\end{array}$ \\
\hline $0-5$ years & $\begin{array}{r}\text { I } \\
\text { II } \\
\text { III } \\
\text { IV }\end{array}$ & $\begin{array}{l}390 \\
268 \\
883 \\
433\end{array}$ & $\begin{array}{r}116.7 \\
46.5 \\
113.2 \\
15.3\end{array}$ & $\begin{array}{r}3 \cdot 34 \\
5 \cdot 76 \\
7 \cdot 80 \\
28 \cdot 33\end{array}$ \\
\hline $5-10$ years & $\begin{array}{l}\text { I } \\
\text { II } \\
\text { III } \\
\text { IV }\end{array}$ & $\begin{array}{r}263 \\
127 \\
206 \\
27\end{array}$ & $\begin{array}{r}94.6 \\
29 \cdot 6 \\
55 \cdot 8 \\
2 \cdot 1\end{array}$ & $\begin{array}{r}2.78 \\
4.29 \\
3.69 \\
12.98\end{array}$ \\
\hline $10-15$ years & $\begin{array}{r}\text { I } \\
\text { II } \\
\text { III }\end{array}$ & $\begin{array}{r}136 \\
45 \\
80\end{array}$ & $\begin{array}{l}66 \cdot 2 \\
20 \cdot 9 \\
33 \cdot 6\end{array}$ & $\begin{array}{l}2 \cdot 05 \\
2 \cdot 16 \\
2 \cdot 38\end{array}$ \\
\hline $15-20$ years & $\begin{array}{r}\text { I } \\
\text { II } \\
\text { III }\end{array}$ & $\begin{array}{l}37 \\
21 \\
16\end{array}$ & $\begin{array}{r}22.3 \\
9.5 \\
13.8\end{array}$ & $\begin{array}{l}1 \cdot 66 \\
2 \cdot 22 \\
1 \cdot 16\end{array}$ \\
\hline
\end{tabular}

was no evidence of an effect on survival of the original stage of the disease. This was slightly earlier than is apparent from figure 2 but was explained by stage III patienț having a higher mean age. The ratio of 1.16 for stage III cases for 15-20 years' follow-up was surprisingly low, but this was probably due to small numbers since there was no significant difference between stages at this point.

Effect of tumour size-We analysed the effect of tumour size on curability for patients with stage I and stage II disease (table III).

TABLE III-Mortality according to size of primary tumour for 1936 women with international stage I or II disease

\begin{tabular}{|c|c|c|c|c|c|c|c|c|}
\hline \multirow{3}{*}{$\begin{array}{c}\text { Tumour } \\
\text { size } \\
(\mathrm{cm})\end{array}$} & \multirow{3}{*}{$\begin{array}{l}\text { No of } \\
\text { cases }\end{array}$} & \multirow{3}{*}{$\begin{array}{l}\left.\text { No (" }{ }^{\prime \prime}\right) \\
\text { surviving } \\
10 \text { years }\end{array}$} & \multicolumn{6}{|c|}{ Ratio $O: E$ deaths at: } \\
\hline & & & \multicolumn{3}{|c|}{$10-15$ years } & \multicolumn{3}{|c|}{$15-20$ years } \\
\hline & & & $\mathrm{O}$ & $\mathrm{E}$ & $\mathrm{O}: \mathrm{E}$ & $\mathrm{O}$ & $\mathrm{E}$ & $\mathrm{O}: \mathrm{E}$ \\
\hline $\begin{array}{r}\leqslant 2 \\
3 \\
4 \\
5\end{array}$ & $\begin{array}{l}543 \\
654 \\
462 \\
277\end{array}$ & $\begin{array}{r}302(56) \\
284(43) \\
174(38) \\
83(30)\end{array}$ & $\begin{array}{l}54 \\
71 \\
38 \\
18\end{array}$ & $\begin{array}{r}31 \cdot 1 \\
26 \cdot 0 \\
22 \cdot 0 \\
7 \cdot 9\end{array}$ & $\begin{array}{l}1.73 \\
2.73 \\
1.73 \\
2.27\end{array}$ & $\begin{array}{r}20 \\
19 \\
13 \\
6\end{array}$ & $\begin{array}{r}10 \cdot 6 \\
10 \cdot 2 \\
8 \cdot 4 \\
2 \cdot 5\end{array}$ & $\begin{array}{l}1.89 \\
1.86 \\
1.55 \\
2.39\end{array}$ \\
\hline
\end{tabular}

Stage III cases were excluded since size was only one of many factors of varying prognostic significance which led to inclusion in stage III. Clearly survival in the first 10 years was strongly related to tumour size, but the situation thereafter was different. The average mortality in the period 10-20 years was around twice that of the normal population but there was no statistical evidence of an effect of tumour size on survival. Similarly, the presence of palpable axillary nodes had no apparent effect beyond 10 years' follow-up. Patients with the earliest disease-that is, a primary tumour $\leqslant 2 \mathrm{~cm}$ with no skin involvement, no palpabie nodes, and no other clinical signs-had a mortality after 10 years 1.74 times that of the normal population, which was not significantly different from the value of 2.01 for stage I and stage II disease combined.

TABLE IV-Mortality according to initial menstrual status for 3232 women with international stage $I, I I$, or III disease

\begin{tabular}{|c|c|c|c|c|c|}
\hline Follow-up & $\begin{array}{l}\text { Menstrual } \\
\text { status }\end{array}$ & $\begin{array}{c}\text { Observed } \\
\text { deaths }\end{array}$ & $\begin{array}{c}\text { Expected } \\
\text { deaths }\end{array}$ & $\begin{array}{l}\text { Ratio } \\
\mathrm{O}: \mathrm{E}\end{array}$ & $\begin{array}{c}\text { Excess } \\
\text { death rate } \\
1000 \\
\text { woman- } \\
\text { years }\end{array}$ \\
\hline $0-5$ years & $\begin{array}{l}\text { Premenopausal } \\
\text { Menopausal } \\
\text { Postmenopausal }\end{array}$ & $\begin{array}{l}389 \\
199 \\
913\end{array}$ & $\begin{array}{r}15.5 \\
11.5 \\
246.7\end{array}$ & $\begin{array}{r}25 \cdot 13 \\
17 \cdot 26 \\
3 \cdot 70\end{array}$ & $\begin{array}{r}97 \cdot 9 \\
133 \cdot 4 \\
100 \cdot 8\end{array}$ \\
\hline $5-10$ years & $\begin{array}{l}\text { Premenopausal } \\
\text { Menopausal } \\
\text { Postmenopausal }\end{array}$ & $\begin{array}{r}153 \\
61 \\
372\end{array}$ & $\begin{array}{r}15 \cdot 4 \\
9 \cdot 7 \\
152 \cdot 2\end{array}$ & $\begin{array}{l}9 \cdot 96 \\
6 \cdot 28 \\
2 \cdot 44\end{array}$ & $\begin{array}{l}54 \cdot 8 \\
64 \cdot 6 \\
65 \cdot 0\end{array}$ \\
\hline $10-15$ years & $\begin{array}{l}\text { Premenopausal } \\
\text { Menopausal } \\
\text { Postmenopausal }\end{array}$ & $\begin{array}{r}73 \\
24 \\
151\end{array}$ & $\begin{array}{l}16 \cdot 3 \\
10 \cdot 0 \\
90 \cdot 2\end{array}$ & $\begin{array}{l}4 \cdot 49 \\
2 \cdot 39 \\
1 \cdot 67\end{array}$ & $\begin{array}{l}32 \cdot 0 \\
25 \cdot 6 \\
36 \cdot 0\end{array}$ \\
\hline $15-20$ years & $\begin{array}{l}\text { Premenopausal } \\
\text { Menopausal } \\
\text { Postmenopausal }\end{array}$ & $\begin{array}{r}24 \\
9 \\
36\end{array}$ & $\begin{array}{r}9 \cdot 2 \\
6 \cdot 3 \\
29 \cdot 5\end{array}$ & $\begin{array}{l}2 \cdot 60 \\
1.43 \\
1.22\end{array}$ & $\begin{array}{l}21.7 \\
11.6 \\
13.8\end{array}$ \\
\hline
\end{tabular}

Effect of menstrual status-This is shown in table IV for the three categories already defined. Stage IV cases were excluded since their survival was so very different from that of non-metastatic patients. Nevertheless, stage IV disease was significantly more common in postmenopausal $(14 \%)$ than premenopausal women $(8 \%)$. For the early periods of follow-up the ratio of observed to expected deaths was greatly increased in premenopausal women because mortality from causes other than breast cancer was extremely low in that age group. This was an indication of the large loss of life expectancy in younger patients with breast cancer but did not imply that their disease was more aggressive than that in older women. For the premenopausal patients in the 15-20-year follow-up period the excess of deaths observed over expected was still significant $(24 v 9 \cdot 2 ; \mathrm{P}<0.01)$; half of these deaths were attributed to breast cancer. For all postmenopausal patients (including those initially in the menopausal group) there was a smaller excess $(45 v 35 \cdot 8 ; \mathrm{P}<0 \cdot 1)$, which was of marginal significance. Since 18 of these deaths were attributed to breast cancer we cannot say that cure was achieved after 15 years in postmenopausal patients. The position was further clarified by considering patients who were disease-free at 15 years. The observed mortality in 204 patients in this category was 33 compared with 30.28 expected, a ratio of 1.09 , which was very close to the desired ratio of unity. This still cannot be interpreted in a totally optimistic way since eight of these deaths were attributed to breast cancer. The excess death rates shown in table IV give some additional information about the effects on survival of menstrual status at presentation. In the first five years of follow-up menopausal patients had an excess mortality more than $30 \%$ greater than that occurring in the premenopausal and postmenopausal groups. Over the next 10 years excess mortality was similar for all three groups, but at 15-20 years premenopausal patients had the highest excess death rate. One additional observation regarding the premenopausal group concerns patients under the age of 35 at presentation. This was a small group of 101 patients, only $44^{\circ}{ }^{\circ}$ of whom survived five years. The situation improved thereafter, with $54 \%$ of five-year survivors still alive after 20 years compared with $37^{\circ}{ }_{\circ}$ of older patients.

\section{Discussion}

The analysis of long-term follow-up data in patients with breast cancer has led some authors to conclude that some women are cured of breast cancer, cure being defined as the achievement of mortality equal to that in the general population. ${ }^{3-5}$ Nevertheless, both groups of authors have pointed out that a significant excess mortality from breast cancer continues even when the ratio of observed to expected death approximates to unity. The question of cure in an absolute sense therefore remains open to question. ${ }^{76-18}$

Our study of 3878 patients is considerably larger than those reported by Brinkley and Haybittle and by Duncan and Kerr and should therefore provide more reliable estimates of curability. The $58^{\circ}{ }_{0}$ excess of deaths in this study from all causes at $15-20$ years' follow-up provides strong evidence that breast cancer patients as a whole cannot be considered cured within 20 years, particularly since this excess includes a twentyfold increase in deaths from breast cancer.

This prolonged increase in mortality should not be interpreted too pessimistically since the excess mortality rate beyond 15 years was less than $2 \%$ per annum. Furthermore, for patients who were disease-free after 15 years the excess mortality rate was just under $1 \%$ per annum, which is of the same order of magnitude as the mortality risk of smoking over 20 cigarettes a day. The long period of follow-up required before a cured group might be identified and the small numbers of patients affected make it difficult to identify prognostically favourable factors which may affect the curability of the disease. ${ }^{19}$ Our study was undertaken to try to determine whether three factors which significantly affect prognosis when fixed-time survival is considered also affect the curability of the disease to the same extent.

The standard of comparison in this study was the Scottish national population, whereas the patients were predominantly from the Edinburgh area, which has a slightly lower mortality. This may mean that the calculated expected deaths are slightly greater than they should be, but such potential bias is very small compared with the mortality risks under consideration. 


\section{EFFECT OF CLINICAL STAGE}

When only fixed-time survival is considered significant differences in survival between the different stages of the disease persist up to 20 years after treatment. ${ }^{13}$ It is interesting to compare this fact with the data presented in figure 2 and table II. From the 10th year onwards there was no clear distinction between patients classified as stage I and those classified as stage II in terms of the mortality of the disease.

The heterogeneity of the group of patients with stage III disease is emphasised by a mortality of $52^{\circ}{ }_{0}$ in the first three years, but those that survived three years have a reasonable prognosis and from 15 years onwards they assumed the same annual mortality of around $5^{\circ}$ as did patients with stage I or stage II disease.

Considering the period 10-20 years as a whole, patients with stage II disease experienced a slightly higher mortality. Over this period the ratio of observed to expected deaths was 1.95, $2 \cdot 17$, and $2 \cdot 02$ for stages I, II, and III respectively.

\section{EFFECT OF TUMOUR SIZE}

The correlation between tumour size and survival from breast cancer is well documented. ${ }^{13} 20$ The effect of this factor on curability was reported by Duncan and Kerr, but their study was restricted to patients with disease confined to the breast on clinical examination. Since, in an unselected series, the proportion of tumours clinically confined to the breast falls progressively as tumour size increases, larger tumours which have no signs of spread may be of a particularly favourable kind. We have therefore examined the effect of size on curability for all cases in stages I and II. The results differ somewhat from those of Duncan and Kerr in that for no tumour size considered did the ratio of observed to expected deaths fall below 1.5 by the fourth quinquennium of follow-up. Like Duncan and Kerr, we found that even for the smallest, most favourable tumours the ratio of observed to expected deaths was significantly raised even at 15-20 years' follow-up. Furthermore, the ratio did not differ from that for the remainder of stages I and II cases.

In this study data on whether axillary nodes were histologically positive was not available and hence it remains an open question whether such histological discrimination could affect curability. It is noteworthy that 21 of Brinkley and Haybittle's 81 survivors at 20 years had had histologically positive nodes at the time of original treatment.

\section{EFFECT OF MENSTRUAL STATUS}

Any consideration of the effect of menstrual status on survival from breast cancer is complicated ty its interrelationship with the age of the patient and by varying attitudes to the definition of the menopause. ${ }^{10}$ We consider the three categories we have used require the fewest assumptions to be made. Patients who are premenopausal, except for the very young, are generally accepted to have a better prognosis, taking account of deaths from all causes, than those who are menopausal or postmenopausal. ${ }^{911}$ 21-24 For older postmenopausal patients this can be attributed to a greater risk of dying from other causes. The data in table IV show that women who were premenopausal at presentation had a significantly increased mortality from breast cancer at 15-20 years from treatment and that postmenopausal patients were in fact the only group that came close to achieving cure in the 20 years.

Patients in the menopausal group are conventionally regarded as carrying the poorest prognosis. In our series this was so in the first five years, when the age-corrected survival $\left(52^{\circ}{ }_{0}^{\circ}\right)$ of menopausal women was significantly lower $(P<0.01)$ than that of the premenopausal group $(62 \%)$ and the postmenopausal group $(61 \%)$. This difference disappeared with longer follow-up, and the smallest excess mortality rate in the 10-20-year follow-up, periods occurred in this group. Our findings have not confirmed recent suggestions that breast cancer is a more aggressive disease in older women. ${ }^{11}{ }^{25}$

\section{CONCLUSION}

Our analysis of survival in a group of patients with breast cancer first treated from 1954 to 1964 and followed up through 1976 has failed to reveal any group of patients who may be considered cured within 20 years, though for postmenopausal patients there is some cause for optimism if they are disease-free after 15 years. Treatment by simple mastectomy and radiotherapy is generally accepted to give results equivalent to more radical surgery plus or minus radiotherapy. ${ }^{26}$ It seems reasonable to conclude that consideration of other series treated by other local techniques would show a similar lack of evidence for a cured group of cases. It remains to be seen whether the recent approach of combining surgery plus or minus radiotherapy with adjuvant chemotherapy or hormone therapy will significantly alter this picture. These results also raise questions about the need for a radical approach to the treatment of the primary tumour. Since there is no evidence that such an approach is associated with the cure of the disease trials of more conservative primary treatment may therefore be justified.

We are grateful to a large number of colleagues, past and present, and to the department of radiotherapy, Edinburgh, for access to case records, the high quality of which made this study possible. We wish to thank Mr W Lutz of the medical computing and statistics unit, Edinburgh, for making our collaboration possible.

Requests for reprints should be addressed to SJP.

\section{References}

1 Cutler, S J, and Myers, M H, Fournal of the National Cancer Institute, 1967, 39, 193.

2 Cutler, S J, Axtell, L M, and Schottenfeld, D, Fournal of Chronic Diseases, 1969, 22, 485.

${ }^{3}$ Brinkley, D, and Haybittle, J L, Lancet, 1975, 11, 95.

- Brinkley, D, and Haybittle, J L, World fournal of Surgery, 1977, 1, 287.

5 Duncan, W, and Kerr, G R, British Medical fournal, 1976, 2, 781.

${ }^{6}$ Easson, E C, and Russell, M H, The Curability of Cancer in Various Sites, p 59. London, Pitman, 1968.

7 Bond, W H, in Proceedings of a Symposium on the Treatment of Carcinoma of the Breast, ed A S Jarrett. Amsterdam, Excerpta Medica, 1968.

${ }^{8}$ Mueller, C B, and Jeffries, W, Annals of Surgery, 1975, 182, 334.

${ }^{9}$ Cutler, S J, Asire, A J, and Taylor, S G, Cancer, 1970, 26, 938.

10 Langlands, A O, and Kerr, G R, Clinical Oncology. In press.

${ }_{11}$ Mueller, C B, Ames, P, and Anderson, G D, Surgery, 1978, 88, 123.

12 TNM Classification of Malignant Tumours. Geneva, International Union Against Cancer, 1958.

${ }^{13}$ Langlands, A O, and Kerr, G R, Clinical Radiology, 1978, 29, 599.

${ }_{14}$ McWhirter, R, British fournal of Radiology, 1955, 28, 128.

15 Breslow, N E, International Statistical Review, 1975, 43, 45.

16 Campos, J L, British fournal of Radiology, 1972, 45, 31.

17 Mackinnon, A, Lancet, 1954, 1, 251.

18 Park, W W, and Lees, J C, Surgery, Gynecology and Obstetrics, 1951, 93, 129.

${ }^{19}$ Myers, M H, Axtell, L M, and Zelen, M, fournal of Chronic Diseases, 1966, 19, 923.

${ }^{20}$ Fisher, B, Slack, N H, and Bross, I D J, Cancer, 1969, 24, 1071.

${ }^{21}$ McKenzie, A, Lancet, 1955, 2, 1129.

${ }^{22}$ Richards, G E, British fournal of Radiology, 1948, 21, 109.

${ }^{23}$ Stoll, B A, Clinical Oncology, 1976, 2, 73.

24 Tough, I C K, Fournal of the Royal College of Surgeons of Edinburgh, 1969, 14, 337.

${ }_{25}$ British Medical fournal, 1979, 1, 211.

${ }^{26}$ Stewart, H J, World fournal of Surgery, 1977, 1, 309.

(Accepted 3 September 1979) 